\title{
АДМИНИСТРАТИВНО-ПРАВОВЫЕ СРЕДСТВА ОБЕСПЕЧЕНИЯ БЕЗОПАСНОСТИ ОБЪЕКТОВ ТОПЛИВНО-ЭНЕРГЕТИЧЕСКОГО КОМПЛЕКСА
}

Актуальность данной статьи обусловлена как теоретическими, так и практическими предпосылками. Теоретическая значимость соответствующих разработок связана с тем, что в настоящее время в научной литературе по административному праву не содержится единого подхода к определению понятия административно-правовых средств обеспечения безопасности объектов топливно-энергетического комплекса, не определены ключевые разновидности таких средств. Практическое значение исследования вопросов обеспечения безопасности объектов топливно-энергетического комплекса определяется тем, что от их бесперебойного функционирования зависит дальнейшее экономическое развитие государства, поскольку они продолжают оставаться основным источником поступлений финансовых ресурсов в бюджет, а возможные акты незаконного вмешательства могут причинить значительный материальный ущерб. Немаловажное значение для обеспечения безопасности объектов топливно-энергетического комплекса имеет организационно-управленческая деятельность государства, которая связана с реализацией исполнительной власти и находит выражение в различных административно-правовых средствах предупреждения, пресечения и наказания, что в комплексе обеспечивает безопасность и антитеррористическую защищённость таких объектов гарантируя недопущение возможных актов незаконного вмешательства. В данной статье сформулировано определение понятия административно-правовых средств обеспечения безопасности объектов топливно-энергетического комплекса. Научная новизна статьи состоит в том, что на основе проведённого анализа законодательства о безопасности объектов топливно-энергетического комплекса и практики его применения выявлены недостатки нормативно-правового регулирования, касающиеся категорирования указанных объектов, а также обеспечения безопасности объектов, подпадающих под действие не только Федерального закона «О безопасности объектов топливно-энергетического комплекса), но и законодательства, обеспечивающего безопасность на транспорте, и сформулированы соответствующие предложения по их устранению.

Ключевые слова: административно-правовые средства, обеспечение безопасности, объекты топливно-энергетического комплекса, категорирование объектов топливно-энергетического комплекса, контрольно-надзорная деятельность.

\section{ADMINISTRATIVE-LEGAL MEANS OF ENSURING SAFETY OF OBJECTS OF FUEL} AND ENERGY COMPLEX

The relevance of this article is due to both theoretical and practical prerequisites. The theoretical significance of the relevant developments is due to the fact that at present the scientific literature on administrative law does not contain a unified approach to the definition of the concept of administrative and legal means of ensuring the safety of fuel and energy complex objects, the key varieties of such means are not defined. The practical significance of the research questions of safety of objects of fuel and energy complex by the fact that their smooth functioning depends on the further economic development of the state as they continue to be the main source of income of financial resources in the budget, and possible acts of unlawful interference can cause significant material damage. The organizational and managerial activity of the state is of great importance for ensuring the safety of fuel and energy facilities. It relates to the implementation of the executive power and is expressed in various administrative and legal means of prevention, sup- pression and punishment, which in combination ensures the safety and anti-terrorist protection of such facilities, providing the prevention of possible acts of unlawful interference. In this article the definition of the concept of administrative and legal means of ensuring the safety of fuel and energy complex objects is formulated. The scientific novelty of the article lies in the fact that on the basis of the analysis of the legislation on the safety of fuel and energy complex objects and the practice of its application, the shortcomings of legal regulation concerning the categorization of these objects, as well as ensuring the safety of objects falling under the action of not only the Federal law "On the safety of objects of the fuel and energy complex", but also the legislation ensuring the safety in transport, and formulated appropriate proposals to eliminate them.

Key words: administrative and legal means, security, objects of fuel and energy complex, categorization of objects of fuel and energy complex, control and supervisory activity.
Обеспечение безопасности объектов топливно-энергетического комплекса имеет существенное значение для экономики Российской Феде- рации в целом, поскольку от бесперебойного их функционирования зависит дальнейшее экономическое развитие государства. Объекты то- 
пливно-энергетического комплекса по-прежнему остаются основным источником поступлений финансовых ресурсов в бюджет, а возможные акты незаконного вмешательства могут причинить значительный экономический урон. В связи с этим важную роль в обеспечении безопасности объектов топливно-энергетического комплекса играет организационно-управленческая деятельность государства, которая находится в плоскости реализации исполнительной власти, что находит отражение в различных административно-правовых средствах упреждающего, пресекательного и карательного характера, которые в совокупности обеспечивают безопасность и антитеррористическую защищённость таких объектов, гарантируя недопущение актов незаконного вмешательства.

Понятие «административно-правовые средства» в последнее время стало достаточно часто употребляться в научных исследованиях. Оно является производным от категории «правовые средства», указывая на отраслевую принадлежность таких средств. В свою очередь правовые средства как правовая категория подвергнуты обширной теоретико-правовой разработке, однако, с концептуальной точки зрения, не выработан единый подход к механизму реализации права как к специальному научному направлению, призванному обеспечить оптимальное использование правовых средств при осуществлении юридической деятельности

Система современных специально-юридических средств не реализуется в необходимой мере, что определяется многообразием подходов к их теоретическому содержанию, а также отсутствием унифицированного подхода субъектов нормотворческой деятельности к пониманию сущности правовых средств и их соотношения с субъективным правом. Проблемы правовых средств актуализируются в юридических научных исследованиях и связаны с необходимостью определить наиболее эфффективные пути и конкретизировать способы достижения целей, которые соответствуют общественным интересам, в охваченных правом сферах жизнедеятельности общества.

Дпя определения понятия административно-правовых средств нужно рассмотреть дефиницию «правовое средство», подвергнутую исследованиям в общей теории права

По мнению П. В. Попинова, правовые средства нужно рассматривать в качестве предусмотренных нормами права и обусловленных определёнными целями и задачами инструментов правового регулирования [9, с. 358-359].

Как полагаетА. В. Кузьмин, правовые средстваэто предусмотренные правовыми нормами, отражающие информационно-энергетические ресурсы права, обеспеченные принудительной силой государства технологии и инструменты, посредством которых достигаются рациональные юридические цели и порождаются соответствующие юридические последствия [3, с. 1].

Согласно дефиниции Ю. Б. Батуриной, правовые средства - это деятельностно-институцио- нальные образования, показывающие функционально-динамическую сторону права в целом и правовых явлений в частности $[1$, с. 8].

Согласно точке зрения А.В. Малько, правовые средства представляют собой правовые явления, которые выражаются в деяниях (технологиях) и инструментах (установлениях), при помощи которых реализуются интересы субъектов права, а также обеспечивается достижение позитивно значимых целей [4, с. 463]. Если исходить из указанного определения, то административно-правовыми средствами обеспечения безопасности объектов топливно-энергетического комплекса являются правовые установления, а также правовые технологии, реализуемые органами исполнительной власти и иными субъектами государственного управления для обеспечения безопасности объектов топливно-энергетического комплекса в различных областях применения норм административного права, включая внешнеуправленческую деятельность государственных органов.

Административно-правовые средства находят материальное закрепление в нормах права, правовых установлениях. Это связано с необходимостью их практического использования, претворения их в жизнь, достижения целей государственного управления. В иных случаях понятие административно-правовых средств как нормативных установлений не имело бы смысла.

Административно-правовые средства имеют свойство нормативности. В то же время их не характеризуют общеобязательность и возможность неоднократного применения. Административно-правовые средства следует рассматривать как один из возможных вариантов поведения, характеризующегося «деятельностью», наличием процессуального содержания, направленного на достижение общественно полезных целей, наполнение которых определяется в каждом конкретном случае на основе усмотрения уполномоченных субъектов государственного управления.

Административно-правовые средства воплощаются в действительность посредством волевых юридически значимых действий субъектов государственного управления, совершаемых в рамках системы социальных связей.

Если исходить из содержания законодательства об обеспечении безопасности объектов топливно-энергетического комплекса, можно выявить ряд административно-правовых средств обеспечения безопасности в данном направлении, к числу которых в первую очередь следует отнести осуществление организационно-правовых мероприятий по категорированию объектов топливно-энергетического комплекса. Необходимость реализации подобного рода мер связана с тем, что разные объекты топливно-энергетического комплекса требуют применения разных мер, направленных на обеспечение их физической защиты. На этой основе определяется и содержание организационно-технических действий в целях рационализации и достижения эфрфек- 
тивности управленческой деятельности в данной сфрере. В зависимости от того, относится ли объект топливно-энергетического комплекса к числу критически важных, а также от степени его потенциальной опасности законодатель выделяет три категории таких объектов: объекты высокой средней и низкой категорий опасности [13, ст. 5].

В деятельность по установлению перечня подлежащих категорированию объектов топливноэнергетического комплекса вовлечён ряд субъектов государственного управления, включая высшее должностное лицо субъекта Российской Федерации, которое утверждает данный перечень, руководствуясь представлением коллегиального органа по противодействию терроризму сформированного в соответствующем субъекте Российской Федерации и включающего в свой состав представителей федеральных органов государственной власти, региональных органов исполнительной власти и органов местного самоуправления. Кроме того, для проведения категорирования объекта топливно-энергетического комплекса по решению его субъекта создается комиссия по категорированию данного объекта, в состав которой подлежат включению: а) представители Федеральной службы войск национальной гвардии Российской Федерации, Министерства энергетики Российской Федерации других заинтересованных федеральных и региональных органов исполнительной власти и органов местного самоуправления (по согласованию); б) руководитель субъекта топливно-энергетического комплекса; в) работники объекта обладающие специальными знаниями в области пожарной и промышленной (технологической) безопасности, технологического оборудования, учёта опасных материалов и веществ, контроля за опасными материалами и веществами, а также в области инженерно-технических средств защиты и охраны информации; г) работники структурного подразделения, обеспечивающего гражданскую оборону объекта; д) работники подразделения безопасности и режимно-секретного отдела при их наличии [7, п. 8]. Процедура категорирования заканчивается тем, что соответствующие объекты вносятся в реестр объектов топливно-энергетического комплекса, за ведение которого отвечает Министерство энергетики Российской Федерации как федеральный орган исполнительной власти, реализующий функции по выработке и осуществлению государственной политики и нормативно-правовому регулированию в топливно-энергетическом комплексе.

Вызывают вопросы правовые нормы, требующие создание комиссии по категорированию объекта решением субъекта топливно-энергетического комплекса нахождение во главе такой комиссии руководителя субъекта топливно-энергетического комплекса. Дело в том, что субъект топливно-энергетического комплекса не является публично-властным субъектом, могущим определять деятельность органов исполнительной власти и местного самоуправления, в том числе выделение для участия в работе комиссии по категорированию должностных лиц этих органов. Если обратиться к утверждаемым высшими должностными лицами субъектов Российской Федерации перечням объектов топливно-энергетического комплекса, подлежащих категорированию, то в них входят, например, котельные, шахты, газонаполнительные и компрессорные станции и др. [10]. Нелогичной является ситуация, когда комиссию по категорированию объекта топливно-энергетического комплекса возглавляет руководитель котельной, а под его началом действуют должностные лица Росгвардии, Минэнерго России и других органов исполнительной власти. Представляется, что указанная комиссия должна создаваться решением должностного лица органа, осуществляющего государственное управление в области обеспечения безопасности объектов топливно-энергетического комплекса, то есть Федеральной службы войск национальной гвардии Российской Федерации, которое и должно её возглавлять.

Следует также отметить, что не всегда следует ожидать активности со стороны субъектов топливно-энергетического комплекса в решении вопросов обеспечения его безопасности, поскольку часто они не заинтересованы в проведении соответствующих мероприятий по причине того, что это означает для них дополнительную организационную нагрузку. В связи с этим существующие рекомендательные нормы, принятые органами исполнительной власти, неэффективны. Так, формирование перечня подлежащих категорированию объектов топливно-энергетического комплекса рекомендовано осуществлять на основе предложений субъектов топливно-энергетического комплекса [8]. Однако действительное положение дел состоит в том, что сами эти субъекты часто не выполняют указанную рекомендацию, а обязать их пройти категорирование, включая внесение соответствующего предложения, как показывает судебная практика, не представляется возможным. Например, в одном из судебных решений было указано, что соответствующая рекомендация адресована органам исполнительной власти субъекта Российской Федерации, так как именно к их ведению относится фоомирование перечня, и никоим образом не свидетельствует о том, что субъект топливно-энергетического комплекса должен вносить предложение о его включении в данный перечень и тем более проходить процедуру категорирования [11].

Ещё один проблемный вопрос при категорировании объектов топливно-энергетического комплекса состоит в том, что при его проведении учитывается, в частности, наличие критических элементов объекта топливно-энергетического комплекса, в качестве которых согласно закону рассматриваются потенциально опасные участки (элементы) объекта топливно-энергетического комплекса, совершение акта незаконного вмешательства по отношению к которым приведёт к прекращению нормального функционирования 
указанного объекта, к аварии на нём или к его повреждению. Изложенная формулировка не содержит критериев отнесения к повреждениям и авариям тех или иных последствий актов незаконного вмешательства. Такая позиция законодателя располагает к отнесению любого производственного и непроизводственного участка объекта топливно-энергетического комплекса к числу критических элементов, поскольку актом незаконного вмешательства на любом из них будет вызвано какое-либо повреждение или авария. Фактически как реальный показатель критичности элемента можно рассматривать лишь прекращение нормального функционирования объекта топливно-энергетического комплекса, однако показатели нормального функционирования законодательно не установлены. Представляется, что показателем нормального функционирования объекта должен являться необходимый уровень выполнения его основной задачи, в качестве которой следует рассматривать производство или хранение продукции (тепловой энергии, газа, нефти и др.). Таким образом, как критерий нормального функционирования логично рассматривать производственные показатели объекта топливно-энергетического комплекса по выработке конечной продукции, что может быть выражено в количественном отношении. В специальной литературе по проблемам обеспечения безопасности объектов топливно-энергетического комплекса предлагается критерий прекращения нормального функционирования такого объекта - снижение выдачи продукции более чем на шестьдесят процентов и на срок более двух суток. Помимо этого, ещё одним критерием отнесения потенциально опасного участка к критическим элементам объекта топливно-энергетического комплекса может стать количество пострадавших в результате возможного осуществления актов незаконного вмешательства, которых должно быть не менее десяти человек [6, с. 74-75]. Сообразно этому целесообразно внести соответствующие уточнения в Федеральный закон «О безопасности объектов топливно-энергетического комплекса».

Одной из основных проблем государственно-управленческой деятельности в области обеспечения безопасности объектов топливно-энергетического комплекса является необходимость разграничения полномочий различных органов исполнительной власти, осуществляющих контрольно-надзорную деятельность в данной сфере. Осуществление такой деятельности также относится к административно-правовым средствам обеспечения безопасности объектов топливно-энергетического комплекса. Дело в том, что существуют объекты, требования к безопасности которых одновременно содержатся в разных федеральных законах и иных нормативных правовых актах. С этим связаны существование различных критериев их категорирования, проведение обследований, дублирующих друг друга, и подготовка совпадающих по многим показателям паспортов безопасности.
Отдельные объекты топливно-энергетического комплекса подпадают под требования таких нормативных правовых актов, как Федеральный закон от 9 февраля 2007 г. №16-Ф3 (в ред. от 03.08.2018 г.) «О транспортной безопасности» [12], Воздушный кодекс Российской Федерации от 19 марта 1997 г. №60-Ф3 (в ред. от 03.08.2018 г.) [3], Международный кодекс по охране судов и портовых средств от 12 декабря 2002 г. [5] Речь идёт о нефтебазах и заводах, на территории которых расположена часть обеспечивающей их функционирование транспортной инфраструктуры, топливозаправочных комплексах авиатранспортной инфраструктуры, морских терминалах. Указанные объекты подвергаются контрольно-надзорным мероприятиям со стороны не только Росгвардии, но и Федеральной службы по надзору в сфере транспорта, а предмет проверки при этом частично совпадает. С одной стороны, такая ситуация обусловливается положениями Федерального закона «О безопасности объектов топливно-энергетического комплекса», согласно которым потенциально опасными объектами топливно-энергетического комплекса являются объекты топливно-энергетического комплекса, на которых в том числе транспортируются взрыво-, пожароопасные, радиоактивные и опасные биологические и химические вещества, а актами незаконного вмешательства на них может быть вызвано возникновение чрезвычайных ситуаций с опасными социально-экономическими последствиями.

С другой стороны, требования, например, к авиатранспортной инфраструктуре применительно к объектам топливно-энергетического комплекса устанавливаются Воздушным кодексом Российской Федерации, согласно ст. 47 которого во второй подзоне приаэродромной территории размещаются объекты, предназначенные для хранения авиационного топлива и заправки воздушных судов и обеспечения энергоснабжения. Соответственно, контрольно-надзорную деятельность в данном случае осуществляют не только орган, обеспечивающий транспортную безопасность (Ространснадзор), но и орган, выполняющий функции по контролю и надзору в области обеспечения безопасности топливно-энергетического комплекса (Росгвардия). Однако это означает дублирование полномочий, выполнение проверочных мероприятий в отношении обеспечения безопасности одних и тех же объектов различными органами, предъявление ими противоречащих друг другу требований и, соответственно, нарушение прав и законных интересов юридических лиц, что требует корректировки законодательства в данной сфере.

Подводя итог, следует отметить, что административно-правовые средства обеспечения безопасности объектов топливно-энергетического комплекса составляют важнейшую часть государственной политики в этой области отношений, однако имеются недостатки нормативно-правового регулирования, касающиеся категорирования 
указанных объектов, а также обеспечения безопасности объектов, подпадающих под действие не только Федерального закона «О безопасности объектов топливно-энергетического комплекса», но и законодательства, обеспечивающего безопасность на транспорте.

\section{Литература}

1. Батурина Ю. Б. Правовая форма и правовое средство в системе понятий теории права: дисс. ... канд. юрид. наук. М., 2001. 149 c.

2. Воздушный кодекс Российской Федерации от 19 марта 1997 г. №60-Ф3 // Собрание законодательства Российской Федерации. 1997. №12. Ст. 1383.

3. Кузьмин А. В. Правовые средства правовосстановления. Понятие и признаки правовых средств // Theory and Practice of the restoration of rights. 2013. №1. C. 1-10.

4. Матузов Н. И., Малько А. В. Теория государства и права: учебник. М.: Юристъ, 2004. 512 с

5. Международный кодекс по охране судов и портовых средств от 12 декабря 2002 г. // Бюллетень международных договоров. 2011. 4.5. Приложение №1.

6. Ничиков А. Проблемные вопросы при категорировании объектов ТЭК // Безопасность объектов ТЭК. 2016. № 1 C. $72-75$.

7. Постановление Правительства РФ от 5 мая 2012 г. № 459 «Об утверждении Положения об исходных данных для проведения категорирования объекта топливно-энергетического комплекса, порядке его проведения и критериях категорирования» // Собрание законодательства Российской Федерации. 2012. №20. Ст. 2556.

8. Приказ Минэнерго России от 10 февраля 2012 г. № 48 «Об утверждении методических рекомендаций по включению объектов топливно-энергетического комплекса в перечень объектов, подлежащих категорированию» // Доступ из СПС «КонсультантПлюс».

9. Проблемы теории государства и права: учебное пособие / под ред. М. Н. Марченко. М.: Юристь, 2001. 656 с

10. Распоряжение Губернатора Ивановской области от 28 сентября 2012 г. №226-р «Об утверждении Перечня объектов топливно-энергетического комплекса Ивановской области, подлежащих категорированию» // Доступ из СПС «КонсультантПлюс. Региональное законодательство».

11. Решение Змеиногорского городского суда Алтайского края от 12 марта 2014 г. по делу № 2-48/2014 // Государственная автоматизированная система Российской Федерации «Правосудие». URL: https://bsr.sudrf.ru/bigs/portal.html (Дата обращения: 17.10.2018).

12. Федеральный закон от 9 февраля 2007 г. № 16-Ф3 «О транспортной безопасности» // Собрание законодательства Российской Федерации. 2007. №7. Ст. 837.

13. Федеральный закон от 21 июля 2011 г. №256-Ф3 «О безопасности объектов топливно-энергетического комплекса» // Собрание законодательства Российской Федерации. 2011. №30. Ст. 604.

\section{References}

1. Baturina Yu. B. Pravovaya forma i pravovoe sredstvo v sisteme ponyatii teorii prava (Legal form and legal means in the system of concepts of the theory of law): thesis. Moscow, 2001.149 p. (In Russian).

2. Vozdushnyi kodeks Rossiiskoi Federatsii No. 60 (The air code of the Russian Federation) (19.03.1997) // Sobranie zakonodatel'stva Rossiiskoi Federatsii. 1997. No. 12. Art. 1383. (In Russian).

3. Kuz'min A. V. Pravovye sredstva pravovosstanovleniya. Ponyatie i priznaki pravovykh sredstv (Legal means of legal restoration. Concept and features of /egal means) // Theory and Practice of the restoration of rights. 2013. No. 1. P. 1-10.

4. Matuzov N. I., Mal'ko A. V. Teoriya gosudarstva i prava (Theory of state and law). Moscow: Yurist, 2004. 512 p. (In Russian).

5. Mezhdunarodnyi kodeks po okhrane sudov i portovykh sredstv (International ship and port facility security code) (12.12.2002) // Byulleten' mezhdunarodnykh dogovorov. 2011. Part 5. Prilozhenie No.1.

6. Nichikov A. Problemnye voprosy pri kategorirovanii obs)ektov TEK (Problematic issues in the categorization of fuel and energy facilities) // Bezopasnost' ob») ektov TEK. 2016. No.1. P. 72-75. (In Russian).

7. Resolution Of The Government Of The Russian Federation No. 459 «Ob utverzhdenii Polozheniya ob iskhodnykh dannykh dlya provedeniya kategorirovaniya ob»ekta toplivno-energeticheskogo kompleksa, poryadke ego provedeniya i kriteriyakh kategorirovaniya" ("On the statement of Regulations on initial data for carrying out categorization of object of fuel and energy complex, the order of its carrying out and criteria of categorization») (05.05.2012) // Sobranie zakonodatel'stva Rossiiskoi Federatsii. 2012. No. 20. Art. 2556. (In Russian).

8. Order Of The Ministry Of Energy No. 48 «Ob utverzhdenii metodicheskikh rekomendatsii po vklyucheniyu ob»ektov toplivno-energeticheskogo kompleksa v perechen' ob»ektov, podlezhashchikh kategorirovaniyu» ("On the approval of methodical recommendations about inclusion of objects of fuel and energy complex in the list of the objects which are subject to categorization») (10.02.2012) // Access from the legal reference system «ConsultantPlus». (In Russian).

9. Problemy teorii gosudarstva i prava: Uchebnoe posobie / Pod red. M. N. Marchenko (Problems of theory of state and law). Moscow: Yurist publ., 2001. 656 p. (In Russian).

10. Order Of the Governor of the Ivanovo region No. 226 «Ob utverzhdenii Perechnya ob» ektov toplivno-energeticheskogo kompleksa Ivanovskoi oblasti, podlezhashchikh kategorirovaniyu» ("On the approval of the List of the objects of fuel and energy complex of the Ivanovo region which are subject to categorizationy) (28.09.2012) / Access from the legal reference system «ConsultantPlus. Regional legislation». (In Russian).

11. The decision of the city court Zmeinogorsk of Altai Krai No.2 - 48/2014 (12.03.2014) // Gosudarstvennaya avtomatizirovannaya sistema Rossiiskoi Federatsii «Pravosudie». URL: https://bsr.sudrf.ru/bigs/portal.html (Accessed: 17.10.2018). (In Russian). 
12. The Federal Law No. 16 "O transportnoi bezopasnosti» ("On transport security») (09.02.2007) // Sobranie zakonodatel'stva Rossiiskoi Federatsii. 2007. No. 7. Art. 837. (In Russian).

13. The Federal Law No. 256 "O bezopasnosti ob»ektov toplivno-energeticheskogo kompleksa» ("On safety of objects of fuel and energy complex») (21.07.2011) // Sobranie zakonodatel'stva Rossiiskoi Federatsii. 2011. No.30. Art.4604. (In Russian).

\section{Сведения об авторе}

Спицына Татьяна Александровна - соискатель кафедры административного и муниципального права Саратовской государственной юридической академии (Саратов) / T.Lobko@mail.ru

\section{Information about the author}

Spitsyna Tat'yana - postgraduate student, Chair of Administrative and Municipal Law, Saratov State Law Academy (Saratov) / T.Lobko@mail.ru 